\title{
Phase Transition of Waxy and Normal Wheat Starch Granules during Gelatinization
}

\author{
Pei Chen, ${ }^{1}$ Xingxun Liu, ${ }^{2}$ Xiao Zhang, ${ }^{1}$ Parveen Sangwan, ${ }^{3}$ and Long Yu ${ }^{4}$ \\ ${ }^{1}$ College of Food Science, South China Agricultural University, Guangzhou 510642, China \\ ${ }^{2}$ Institute of Agro-Products Processing Science and Technology (IAPPST), Chinese Academy of Agricultural Science (CAAS), \\ Beijing 100193, China \\ ${ }^{3}$ Commonwealth Scientific \& Industrial Research Organization, Materials Science and Engineering, Melbourne, VIC 3169, Australia \\ ${ }^{4}$ School of Light Industry and Food Science, CFPFRR, South China University of Technology, Guangzhou 510640, China
}

Correspondence should be addressed to Pei Chen; peichen@scau.edu.cn and Long Yu; longyuau@gmail.com

Received 22 September 2014; Revised 29 December 2014; Accepted 6 January 2015

Academic Editor: Önder Pekcan

Copyright (C) 2015 Pei Chen et al. This is an open access article distributed under the Creative Commons Attribution License, which permits unrestricted use, distribution, and reproduction in any medium, provided the original work is properly cited.

\begin{abstract}
The phase transition of waxy and normal wheat starches was systematically studied by light microscopy (LM) with a hot-stage, confocal laser scanning microscopy (CLSM) and differential scanning calorimetry (DSC). While being heated in water, waxy wheat starch showed a higher gelatinization enthalpy than that for the normal starch, which was also verified by the changes in birefringence. As confirmed by LM and CLSM, starch granules displayed an increased swelling degree with temperature increasing, and the gelatinization initially occurred at the hilum (botanical center) of the granules and then spread rapidly to the periphery. While the temperature range of birefringence was narrower than that of granule size change, the crystalline structure was melted at lower temperatures than those for the molecular orders. These results indicate that starch gelatinization was a complex process rather than a simple order-to-disorder granule transition.
\end{abstract}

\section{Introduction}

Starch is a kind of carbohydrate and is widely employed in food and nonfood industries. It is well known that starch is a mixture of amylose (a linear structure of alpha-1, 4 linked glucose units) and amylopectin (a highly branched structure of short alpha-1, 4 chains linked by alpha-1, 6 bonds). The ratio of amylose and amylopectin depends on the biological genetics backgrounds. Normal wheat starches consist of 22$35 \%$ amylose and 65-78\% amylopectin while waxy (amylosefree) wheat starches contain essentially $100 \%$ amylopectin [1]. The waxy wheat starch was first developed in Japan through genetic modification [2]. Recently, the waxy wheat starches have attracted increasing attention. Various waxy wheat cultivars were developed by using rolling convergent backcross method combining with pollen and endosperm staining with $\mathrm{I}_{2}$-KI solution in China [3].

The term of "gelatinization" is usually used to describe the phase transition of starch. The highly ordered structure of native starch granules transfers into disordered structure when the starch was heated in excess water, which is known as gelatinization $[4,5]$. The gelatinization always occurs in a certain temperature range which was defined as "gelatinization temperature," and the gelatinization temperature is one of the most important technical indicators to evaluate the quality of starch glue. During gelatinization, starch granules absorb water and swell, showing a series of changes such as volume, viscosity, and crystallinity, which are used to evaluate the extent of starch gelatinization. The ratio of amylose and amylopectin and the structure of starch granules influence the physicochemical properties and the phase transition of starch and finally affect product performance [6]. In the past decades, waxy wheat breeding, physicochemical properties, and starch granule structure of waxy wheat starch have been widely studied [7-9]. However, there are few reports on the phase transition of waxy wheat starch.

In the last 20 years, many techniques have been developed to study the phase transition during gelatinization, including 
light microscopy [10-12], differential scanning calorimetry (DSC) $[13,14]$, and X-ray diffraction (XRD) [15]. The DSC is used to study the changes in enthalpy during gelatinization. The light microscopy is used to observe granular swelling and crystallization behavior during gelatinization. Recently, the confocal scanning laser microscopy (CLSM) is used for the observation of the changes within starch granule from the three-dimensional angle during gelatinization. It can be used to directly observe the cross-sections of starch granules without destructing sample and thus was recognized as a very effective way to study the gelatinization mechanism synchronously.

The aim of this work is to further explore the changes in inner structure of the wheat starch granules during gelatinization, especially the effect of the amylose content on wheat starch gelatinization, and understand the relationship between structure and thermal behavior of starch. The changes in granule size, the birefringence, and the enthalpy were used to describe the phase transition during gelatinization. Although some works about phase transitions of waxy wheat starch have been reported [1], nobody conducts the research about the changes in inner structure of waxy wheat starch during gelatinization.

\section{Experimental}

2.1. Materials. A spring wheat cultivar Chinese spring (CS) wheat and its near-isogenic waxy type were used in this work. A waxy wheat line "Caiwx" and Yangmai01-2 were used as donor and recurrent parents, respectively. The waxy wheat was developed by using rolling convergent backcross method combined with pollen and endosperm staining with $\mathrm{I}_{2}-\mathrm{KI}$ solution. These two types of wheat cultivar were grown at the same environmental conditions at the bay head bas, Lixiahe region in Jiangsu Institute of Agricultural Sciences, China, in 2010 under ordinary conditions and their seeds were used.

Whole wheat grains were milled with an experimental mill (Shijiazhuang ring in mechanical equipment Co. Ltd., China) to produce $60 \%$ flour extraction. The starches were isolated using a dough-washing method: two hundred grams flour was mixed with $120 \mathrm{~mL}$ distilled water to produce a consistent dough and after 30 minutes of resting, the dough was washed by tap water to separate starch from gluten. The starch was then dried at $40^{\circ} \mathrm{C}$ for $24 \mathrm{~h}$ and the dried starch was washed again with ethanol and acetone to remove free sugars.

The apparent amylose content of starch was determined by iodine binding as described by Chrastil [17].

2.2. Microscope with Hot-Stage. A polarization microscope (Axioskop 40 Pol/40 A Pol, ZEISS, Oberkochen, Germany) equipped with a $35 \mathrm{~mm}$ SLA camera and a heating stage (CI94, Linkam Scientific Instruments Ltd.) was used to observe the changes in starch granules size and birefringence during gelatinization. Suspensions with $0.5 \%$ starch were prepared between glass and cover slips to study their phase transition. Each specimen was heated from room temperature to $100^{\circ} \mathrm{C}$ at $2^{\circ} \mathrm{C} / \mathrm{min}[10,18]$. To prevent water evaporation silicon glue was used. The camera interval timer was set as $30 \mathrm{~s}$ so that an image was captured at each $1^{\circ} \mathrm{C}$ temperature increase. Each field was photographed under normal and polarized light, respectively.

Diameters of starch granules were conducted using the Gun Image Manipulation Program. More than 200 particles were calculated for each sample and the results were based on the average of the measurement.

2.3. Confocal Laser Scanning Microscopy. Starch samples were prepared for CLSM essentially as previous description [19]. $10 \mathrm{mg}$ starch granules were dispersed in $15 \mu \mathrm{L}$ of freshly made 8-aminopyrene-1,3,6-trisulfonic acid, trisodium salt (APTS) solution (10 mM APTS dissolved in $15 \%$ acetic acid), and $15 \mu \mathrm{L}$ of $1 \mathrm{M}$ sodium cyanoborohydride was added. The reaction mixture was incubated at $30^{\circ} \mathrm{C}$ for $15-18 \mathrm{~h}$. The granules were washed 5 times with $1 \mathrm{~mL}$ of distilled water and finally suspended in $1 \mathrm{~mL}$ of distilled water in a glass vial. Then, the glass vials were placed in the water bath $\left(55^{\circ} \mathrm{C}, 60^{\circ} \mathrm{C}\right.$, and $65^{\circ} \mathrm{C}$ ) for $2 \mathrm{~min}$. After thermal treatment, the samples were immediately cooled with fluid tap water. Then, a drop of the mixture mounted on a glass plate for microscopy.

A confocal laser scanning microscope equipped with an $\mathrm{Ar} / \mathrm{Hg}$ laser (TCS SP2, Leica Microsystems, Wetzlar, Germany) with a stand for fixed fluorescent cell samples was used to investigate the internal morphologies of wheat starches. The Leica objective lens used were 60x plan apo/1.40 oil UV. During image acquisition, each line was scanned four times and averaged to reduce noise.

2.4. Differential Scanning Calorimeter (DSC). A PerkinElmer DSC Diamond-I with an internal coolant (Intercooler 1P) and nitrogen purge gas was used in the experimental work to visualize the gelatinization behaviors. High pressure stainless steel pans (PerkinElmer number B0182901) with a gold plated copper seal (PerkinElmer number 042-191758) were used to study the thermal behaviors up to $180^{\circ} \mathrm{C}$ with $75 \%$ moisture content. The heating rate of $2^{\circ} \mathrm{C} / \mathrm{min}$ was used to match the observations under the microscope with the hot-stage and to minimize any temperature lag due to the large mass of the samples.

2.5. Statistical Analysis. All the experiments were repeated 3 times to reduce experimental error. All statistical analysis was performed in Origin (version 6.0, OriginLab (Guangzhou) Ltd., Guangzhou, China) for Windows.

\section{Results and Discussion}

The amylose contents of waxy wheat starch and normal wheat starch are $2.6 \%$ and $27 \%$, respectively. The phase transition of waxy and normal wheat starch was studied with a microscope with a hot-stage. The samples were heated at $2^{\circ} \mathrm{C} / \mathrm{min}$ under high water content and the changes in granular morphology and birefringence under normal and polarized light were recorded automatically every $30 \mathrm{~s}$ during heating. Table 1 shows microscope images taken at different temperatures. The images under polarized light were taken at the same 
position of those under normal light. The images collected at $30^{\circ} \mathrm{C}$ represent the initial morphologies of the waxy and normal wheat starches. It can be seen that both waxy and normal wheat starch contain two types of starch granules, commonly referred to as A-type and B-type granules [20]. Atype granules are disk-like or lenticular shape with smooth surface, whereas B-type granules possess a spherical or angular morphology. Both native normal and waxy starch granules show the Maltese cross. The birefringence brightness of the waxy granules is higher than that of the normal wheat starch, which indicates that the waxy granules possess higher crystallinity. Similar result has been observed for maize starches $[12,21]$.

These two starches showed gradual changes in granular morphology and semicrystalline black crosses as the temperature increases. It can be seen that the phase transition observed under microscope was nonlinear and the images in Table 1 mainly represent the variation points. For waxy wheat starch, the granule size remained the same before $52^{\circ} \mathrm{C}$ and then the granules size increased with temperature increasing after $52^{\circ} \mathrm{C}$ and birefringence disappeared at $64^{\circ} \mathrm{C}$. These results indicate that the heat-treatment temperature below $52^{\circ} \mathrm{C}$ is not high enough to destroy irreversibly the microstructure of waxy wheat starch granules and to gelatinize waxy wheat starch. For normal wheat starch, the size distributions of starch granules were quite similar to those of native starch below $55^{\circ} \mathrm{C}$, but the birefringence disappeared at $62^{\circ} \mathrm{C}$. It is important to note that the end temperatures when birefringence disappeared are different for waxy and normal wheat starch; waxy wheat starch has higher end temperature. Table 2 lists the observed initial and final temperatures of starch granular swelling and birefringence for waxy and normal wheat starch. Generally, the A-type granules of the waxy and normal wheat starch expanded by $91 \%$ and $96 \%$, respectively, and the B-type granules of waxy and normal wheat starch expanded by $212 \%$ and $115 \%$, respectively. The temperature range of diameter and birefringence for waxy starch were $52 \sim 66^{\circ} \mathrm{C}$ and $57 \sim 64^{\circ} \mathrm{C}$, respectively, which were $55 \sim 67^{\circ} \mathrm{C}$ and $59 \sim 62^{\circ} \mathrm{C}$ for wheat starch, respectively. In other words, the A-type granules of the waxy and normal wheat starch began to swell at about $57 \sim 58^{\circ} \mathrm{C}$ while destroyed at about $63^{\circ} \mathrm{C}$ and $61^{\circ} \mathrm{C}$, respectively. The B-type granules of waxy and normal wheat starch began to swell at about 52 $55^{\circ} \mathrm{C}$ while destroyed at about $66^{\circ} \mathrm{C}$ and $67^{\circ} \mathrm{C}$, respectively. The temperatures of birefringence disappearance were at $64^{\circ} \mathrm{C}$ and $62^{\circ} \mathrm{C}$ for waxy and normal wheat starch. It is easy to notice that the temperature range of birefringence was narrower than that of diameter, which indicated that the loss of crystalline structure occurred at lower temperatures while the loss of molecular order occurred at higher temperature for these two starches during heating. This was expected, since starch granules continuously swell even after the crystalline structure of the starch granules has been destroyed. Besides, the onset temperature of generation obtained with the microscope is corresponding with the data of DSC (Figure 1).

The temperature-induced changes of inner structure of the wheat starch granules under excess water were also studied using CLSM (Table 3). Compared with native wheat starch (see $30^{\circ} \mathrm{C}$ in Table 3), it can be seen that the brightness

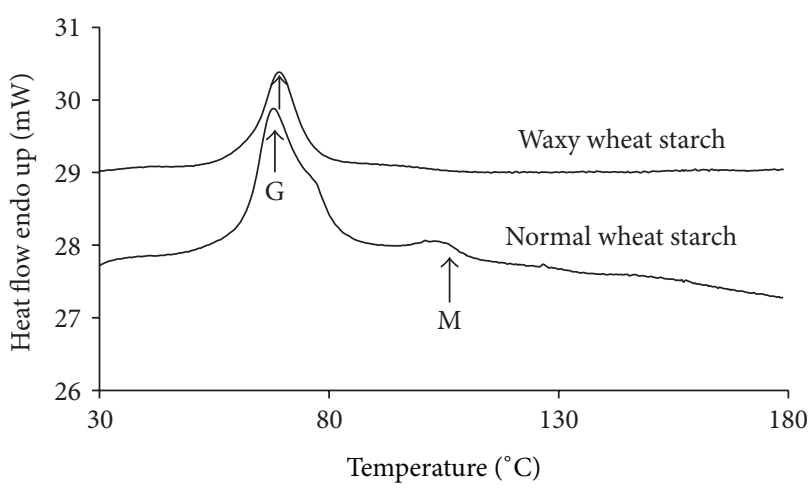

FIGURE 1: DSC gelatinization endotherms of waxy and normal wheat starch with excess water (75\%).

of gelatinized wheat starch decreased with the temperature increasing, which started from the centre of the granules (Table 3). That means that the gelatinization started at the hilum (botanical center) of the granules and then spread rapidly to the periphery. Gelatinization begins in the intercellular areas where the hydrogen bonding is the weakest, and the central area of the granule around the hilum is considered to be the least organized region of the starch granule.

Figure 1 shows the gelatinization endotherms of waxy and normal wheat starches under excess water at temperature range between 30 and $180^{\circ} \mathrm{C}$ measured by DSC. The $T_{o}, T_{p}$, $T_{c}$, and $\Delta H$ calculated from the thermograms are listed in Table 4. Original DSC curves related to the melting of aqueous wheat starch dispersions show the typical endothermic transitions. It is observed that there was a large gelatinization endotherm appearing at about $70^{\circ} \mathrm{C}$ for both waxy and normal wheat starch similar to previous reports [22-24]. This endotherm has been well accepted as the gelatinization of amylopectin and labeled as G endotherm. Table 4 lists the gelatinization characteristics of waxy and normal wheat starch, and the results showed that the peak temperatures of gelatinization and gelatinization enthalpy for waxy wheat starch $\left(69.71^{\circ} \mathrm{C}, 14.62 \mathrm{~J} / \mathrm{g}\right)$ are higher than those of normal wheat starch $\left(68.47^{\circ} \mathrm{C}, 12.22 \mathrm{~J} / \mathrm{g}\right)$, which are in agreement with the previous studies $[2,25]$. But the onset temperature $T_{o}$ and conclusion temperature $T_{c}$ for waxy wheat starch were lower than those of normal wheat starch. The result was consistent with our previous report [6].

Apart from the $G$ endotherm, a second endotherm was also detected for normal wheat starch at about $100^{\circ} \mathrm{C}$. Previous study has reported this endotherm for maize starch, which was considered as the phase transition within an amylose-lipid complex and labeled as M [6]. The first endothermic transition is attributed to the melting of the crystalline lamellae, while the second temperature peak is ascribed to either a melting of incompletely solvated starch crystallites or the dissociation of the amylose-lipid complexes. Because of the low amylose content in waxy wheat starch, the second transition is absent for this type of starch. Generally, all the thermodynamic melting parameters related to both crystalline lamellae and amylose-lipid complexes are in agreement with the previously published data for 
TABLE 1: Images collected at different temperatures for waxy and normal wheat starch under normal and polarized light.

\begin{tabular}{|c|c|c|c|c|}
\hline Temp. & $\begin{array}{l}\text { Waxy wheat starch } \\
\text { (under normal light) }\end{array}$ & $\begin{array}{c}\text { Waxy wheat starch } \\
\text { (under polarized light) }\end{array}$ & $\begin{array}{l}\text { Normal wheat starch } \\
\text { (under normal light) }\end{array}$ & $\begin{array}{l}\text { Normal wheat starch } \\
\text { (under polarized light) }\end{array}$ \\
\hline \multicolumn{5}{|l|}{$30^{\circ} \mathrm{C}$} \\
\hline \multicolumn{5}{|l|}{$50^{\circ} \mathrm{C}$} \\
\hline \multicolumn{5}{|l|}{$55^{\circ} \mathrm{C}$} \\
\hline \multicolumn{5}{|l|}{$57^{\circ} \mathrm{C}$} \\
\hline \multicolumn{5}{|l|}{$59^{\circ} \mathrm{C}$} \\
\hline \multicolumn{5}{|l|}{$61^{\circ} \mathrm{C}$} \\
\hline \multicolumn{5}{|l|}{$63^{\circ} \mathrm{C}$} \\
\hline \multicolumn{5}{|l|}{$65^{\circ} \mathrm{C}$} \\
\hline
\end{tabular}


TABle 1: Continued.

\begin{tabular}{|c|c|c|c|c|}
\hline Temp. & $\begin{array}{l}\text { Waxy wheat starch } \\
\text { (under normal light) }\end{array}$ & $\begin{array}{l}\text { Waxy wheat starch } \\
\text { (under polarized light) }\end{array}$ & $\begin{array}{l}\text { Normal wheat starch } \\
\text { (under normal light) }\end{array}$ & $\begin{array}{l}\text { Normal wheat starch } \\
\text { (under polarized light) }\end{array}$ \\
\hline $67^{\circ} \mathrm{C}$ & & & & \\
\hline $70^{\circ} \mathrm{C}$ & & & & \\
\hline
\end{tabular}

TABLE 2: Observed variation of waxy wheat starch and normal wheat starch.

\begin{tabular}{|c|c|c|c|c|c|c|}
\hline \multirow{2}{*}{\multicolumn{2}{|c|}{$\begin{array}{l}\text { Variation } \\
\text { Materials }\end{array}$}} & \multicolumn{3}{|c|}{ Diameter measured } & \multicolumn{2}{|c|}{ Crystalline detected } \\
\hline & & \multirow{2}{*}{$\begin{array}{c}\text { Initial } \\
\text { temperature }\left({ }^{\circ} \mathrm{C}\right)\end{array}$} & \multirow{2}{*}{$\begin{array}{c}\begin{array}{c}\text { Disappear } \\
\text { temperature }\left({ }^{\circ} \mathrm{C}\right)\end{array} \\
63\end{array}$} & \multirow{2}{*}{$\begin{array}{c}\text { Swelling ratio } \\
(\%)\end{array}$} & \multirow{3}{*}{$\begin{array}{c}\text { Initial temperature }\left({ }^{\circ} \mathrm{C}\right) \\
57\end{array}$} & \multirow{3}{*}{$\begin{array}{c}\text { End temperature }\left({ }^{\circ} \mathrm{C}\right) \\
64\end{array}$} \\
\hline \multirow{2}{*}{ Waxy wheat } & A-type granules & & & & & \\
\hline & B-type granules & 52 & 66 & $212 \pm 5$ & & \\
\hline \multirow{2}{*}{ Normal wheat } & A-type granules & 58 & 61 & $96 \pm 3$ & \multirow{2}{*}{59} & \multirow[t]{2}{*}{62} \\
\hline & B-type granules & 55 & 67 & $115 \pm 4$ & & \\
\hline
\end{tabular}

wheat starches $[22,26-28]$. It is seen that the gelatinization enthalpy of waxy wheat starch is higher than that of normal wheat starch in general. This is expected since enthalpy is the latent heat absorbed by the melting of crystallites in the granules, which depends on a number of factors such as intermolecular bonding, crystallinity, rate of heating of the starch suspension, and presence of other chemicals. Higher gelatinization enthalpy for waxy wheat starch showed that the waxy wheat starch with predominant amylopectin requires higher energy for gelatinization because of its higher crystallinity compared with the normal wheat starch.

The heterogeneity and complexity of starch granular structure influence the phase transition of wheat starch during gelatinization. The proposed phase transition model of wheat starch during gelatinization was consistent with the model of HCl-methanol hydrolysis on starch influenced by starch granular architecture predicted by Chung and Lai [16] (Figure 2). During heating, water primarily diffused from the surface of starch granules into the channels and then the water reached the cavity and later through the channels and finally diffused throughout the granule matrix from the cavity and channels. Based on the diffusion path, the starch was recommended to be divided into 3 regions: the unconsolidated areas located, surrounding cavity and channels (D1), stacking tightly the layer which the water can not easily diffuse in (D3), and the intermediate organized area between D1 and D3 (D2). The possible pathway of water in starch granules during gelatinization started from the central cavity and then spread the whole granule through the channel; the order is D1, D2, and D3.

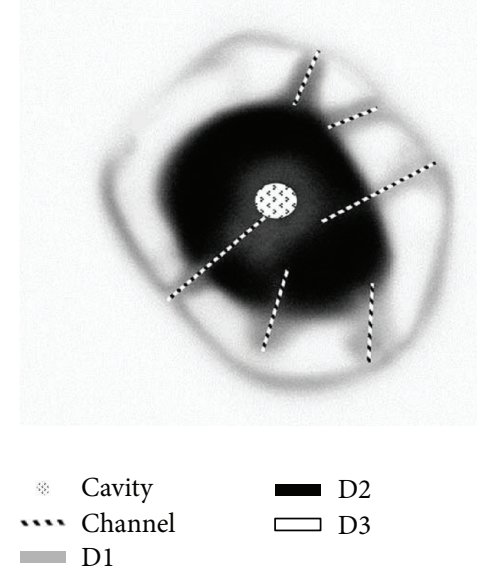

FIGURE 2: A possible model of starch granule during gelatinization [16]. D1: the unconsolidated areas located surrounding cavity and channels. D2: the intermediate organized area. D3: the dense packed layer beneath the outer surface.

\section{Conclusion}

Different microscopic techniques and DSC were used to study the changes in the structure of waxy and normal wheat starch during gelatinization. An increase in starch granule size and disappearance of birefringence and granule were used to describe the phase transition. Swelling of starch granules increased progressively with temperature 
TABLE 3: CLSM optical sections of waxy and normal wheat starch after being particularly gelatinized.

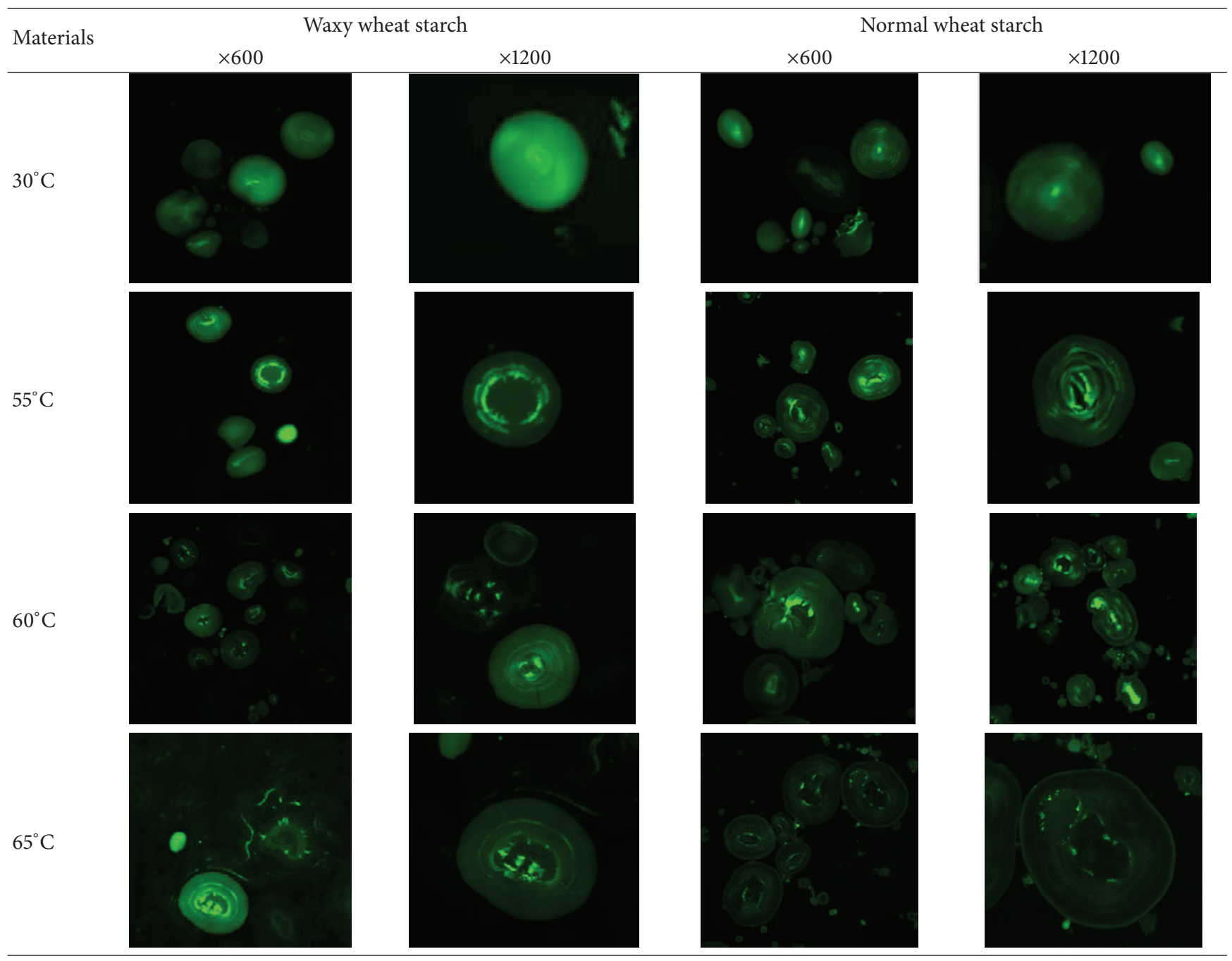

TABLE 4: Gelatinization characteristics of waxy and normal wheat starches detected by DSC.

\begin{tabular}{|c|c|c|c|c|c|c|c|}
\hline \multirow{2}{*}{ Sample } & \multicolumn{3}{|c|}{ Endotherm $1(\mathrm{G})$} & \multicolumn{3}{|c|}{ Endotherm $2(\mathrm{M})$} & \multirow{2}{*}{$\begin{array}{c}\text { Total } \\
\Delta H /(\mathrm{J} / \mathrm{g})\end{array}$} \\
\hline & $T_{o} /{ }^{\circ} \mathrm{C}$ & $T_{p} /{ }^{\circ} \mathrm{C}$ & $T_{c} /{ }^{\circ} \mathrm{C}$ & $T_{o} /{ }^{\circ} \mathrm{C}$ & $T_{p} /{ }^{\circ} \mathrm{C}$ & $T_{c} /{ }^{\circ} \mathrm{C}$ & \\
\hline Waxy wheat starch & $57.32 \pm 0.5$ & $69.71 \pm 0.5$ & $79.78 \pm 0.6$ & - & - & - & $14.62 \pm 0.4$ \\
\hline Normal wheat starch & $58.00 \pm 0.4$ & $68.47 \pm 0.3$ & $83.49 \pm 0.8$ & $98.48 \pm 0.6$ & $105.54 \pm 0.7$ & $112.14 \pm 0.3$ & $12.22 \pm 0.3$ \\
\hline
\end{tabular}

increasing. When being heated, granules underwent structural changes prior to the visible morphological changes taking place during gelatinization. The temperature range of birefringence was narrower than that of granule size, which also indicated that, during heating, the crystalline structure was melted at lower temperatures than those for the molecular orders for these two starch samples. CLSM showed that the gelatinization starts at the hilum (botanical center) of the granules and spread rapidly to the periphery. DSC results showed that waxy wheat starch has higher gelatinization transition enthalpy than normal wheat starch. This is the first time to address the inner structure changes of waxy wheat starch during gelatinization.

\section{Conflict of Interests}

The authors declare that there is no conflict of interests regarding the publication of this paper.

\section{Acknowledgments}

The authors from China would like to acknowledge the research funds NFSC (31101340, 31301554, and 21106023) and GNSF (S2012040006450). This work is also supported by the Open Project Program of Guangdong Province Key Laboratory for Green Processing of Natural Products and Product Safety. 


\section{References}

[1] H. Zhang, W. Zhang, C. Xu, and X. Zhou, "Morphological features and physicochemical properties of waxy wheat starch," International Journal of Biological Macromolecules, vol. 62, pp. 304-309, 2013.

[2] P. V. Hung, T. Maeda, and N. Morita, "Study on physicochemical characteristics of waxy and high-amylose wheat starches in comparison with normal wheat starch," Starch/Staerke, vol. 59, no. 3-4, pp. 125-131, 2007.

[3] P. R. Chang, J. Yu, and X. Ma, "Preparation of porous starch and its use as a structure-directing agent for production of porous zinc oxide," Carbohydrate Polymers, vol. 83, no. 2, pp. 1016-1019, 2011.

[4] L. Wang, B. Xie, G. Xiong, X. Du, Y. Qiao, and L. Liao, "Study on the granular characteristics of starches separated from Chinese rice cultivars," Carbohydrate Polymers, vol. 87, no. 2, pp. 10381044, 2012.

[5] P. Chen, L. Yu, T. Kealy, L. Chen, and L. Li, "Phase transition of starch granules observed by microscope under shearless and shear conditions," Carbohydrate Polymers, vol. 68, no. 3, pp. 495-501, 2007.

[6] H. Liu, L. Yu, F. Xie, and L. Chen, "Gelatinization of cornstarch with different amylose/amylopectin content," Carbohydrate Polymers, vol. 65, no. 3, pp. 357-363, 2006.

[7] J. Xu, Q. Wang, M. Bashari et al., "Branched limit dextrin impact on wheat and waxy starch gels retrogradation," Food Hydrocolloids, vol. 39, pp. 136-143, 2014.

[8] S. Fujita, T. Kumagai, M. Yanagimachi et al., "Waxy wheat as a functional food for human consumption," Journal of Cereal Science, vol. 55, no. 3, pp. 361-365, 2012.

[9] H. Lan, R. Hoover, L. Jayakody et al., "Impact of annealing on the molecular structure and physicochemical properties of normal, waxy and high amylose bread wheat starches," Food Chemistry, vol. 111, no. 3, pp. 663-675, 2008.

[10] A.-I. Yeh and J.-Y. Li, "Kinetics of phase transition of native, cross-linked, and hydroxypropylated rice starches," StarchStaerke, vol. 48, no. 1, pp. 17-21, 1996.

[11] G. R. Ziegler, D. B. Thompson, and J. Casasnovas, "Dynamic measurement of starch granule swelling during gelatinization," Cereal Chemistry, vol. 70, p. 247, 1993.

[12] P. Chen, L. Yu, G. Simon, E. Petinakis, K. Dean, and L. Chen, "Morphologies and microstructures of cornstarches with different amylose-amylopectin ratios studied by confocal laser scanning microscope," Journal of Cereal Science, vol. 50, no. 2, pp. 241-247, 2009.

[13] J. K. Jang, S. H. Lee, S. C. Cho, and Y. R. Pyun, "Effect of sucrose on glass transition, gelatinization, and retrogradation of wheat starch," Cereal Chemistry, vol. 78, no. 2, pp. 186-192, 2001.

[14] H. Liu, L. Yu, G. Simon, X. Zhang, K. Dean, and L. Chen, "Effect of annealing and pressure on microstructure of cornstarches with different amylose/amylopectin ratios," Carbohydrate Research, vol. 344, no. 3, pp. 350-354, 2009.

[15] P. J. Jenkins, R. E. Comerson, A. M. Donald et al., "In situ simultaneous small and wide angle x-ray scattering: a new technique to study starch gelatinization," Journal of Polymer Science Part B: Polymer Physics, vol. 32, no. 8, pp. 1579-1583, 1994.

[16] Y.-L. Chung and H.-M. Lai, "Molecular and granular characteristics of corn starch modified by HCl-methanol at different temperatures," Carbohydrate Polymers, vol. 63, no. 4, pp. 527534, 2006.
[17] J. Chrastil, "Improved colorimetric determination of amylose in starches or flours," Carbohydrate Research, vol. 159, no. 1, pp. 154-158, 1987.

[18] P. Chatakanonda, S. Varavinit, and P. Chinachoti, "Effect of crosslinking on thermal and microscopic transitions of rice starch," LWT_Food Science and Technology, vol. 33, no. 4, pp. 276-284, 2000.

[19] P. Chen, L. Yu, G. P. Simon, X. Liu, K. Dean, and L. Chen, "Internal structures and phase-transitions of starch granules during gelatinization," Carbohydrate Polymers, vol. 83, no. 4, pp. 1975-1983, 2011.

[20] H. Salman, J. Blazek, A. Lopez-Rubio, E. P. Gilbert, T. Hanley, and L. Copeland, "Structure-function relationships in A and B granules from wheat starches of similar amylose content," Carbohydrate Polymers, vol. 75, no. 3, pp. 420-427, 2009.

[21] P. Chen, L. Yu, L. Chen, and X. Li, "Morphology and microstructure of maize starches with different amylose/amylopectin content," Starch/Staerke, vol. 58, no. 12, pp. 611-615, 2006.

[22] V. I. Kiseleva, A. V. Krivandin, J. Fornal, W. Błaszczak, T. Jeliński, and V. P. Yuryev, "Annealing of normal and mutant wheat starches. LM, SEM, DSC, and SAXS studies," Carbohydrate Research, vol. 340, no. 1, pp. 75-83, 2005.

[23] M. Tako, Y. Tamaki, T. Konishi, K. Shibanuma, I. Hanashiro, and Y. Takeda, "Gelatinization and retrogradation characteristics of wheat (Rosella) starch," Food Research International, vol. 41, no. 8, pp. 797-802, 2008.

[24] K. Kohyama, J. Matsuki, T. Yasui, and T. Sasaki, "A differential thermal analysis of the gelatinization and retrogradation of wheat starches with different amylopectin chain lengths," Carbohydrate Polymers, vol. 58, no. 1, pp. 71-77, 2004.

[25] S.-H. Yoo and J.-L. Jane, "Structural and physical characteristics of waxy and other wheat starches," Carbohydrate Polymers, vol. 49, no. 3, pp. 297-305, 2002.

[26] Y. I. Matveev, J. J. G. van Soest, C. Nieman et al., "Relationship between thermodynamic and structural properties of low and high amylose maize starches," Carbohydrate Polymers, vol. 44, no. 2, pp. 151-160, 2001.

[27] T. Noda, S. Tsuda, M. Mori et al., "The effect of harvest dates on the starch properties of various potato cultivars," Food Chemistry, vol. 86, no. 1, pp. 119-125, 2004.

[28] I. Bocharnikova, L. A. Wasserman, A. V. Krivandin et al., "Structure and thermodynamic melting parameters of wheat starches with different amylose content," Journal of Thermal Analysis and Calorimetry, vol. 74, no. 3, pp. 681-695, 2003. 

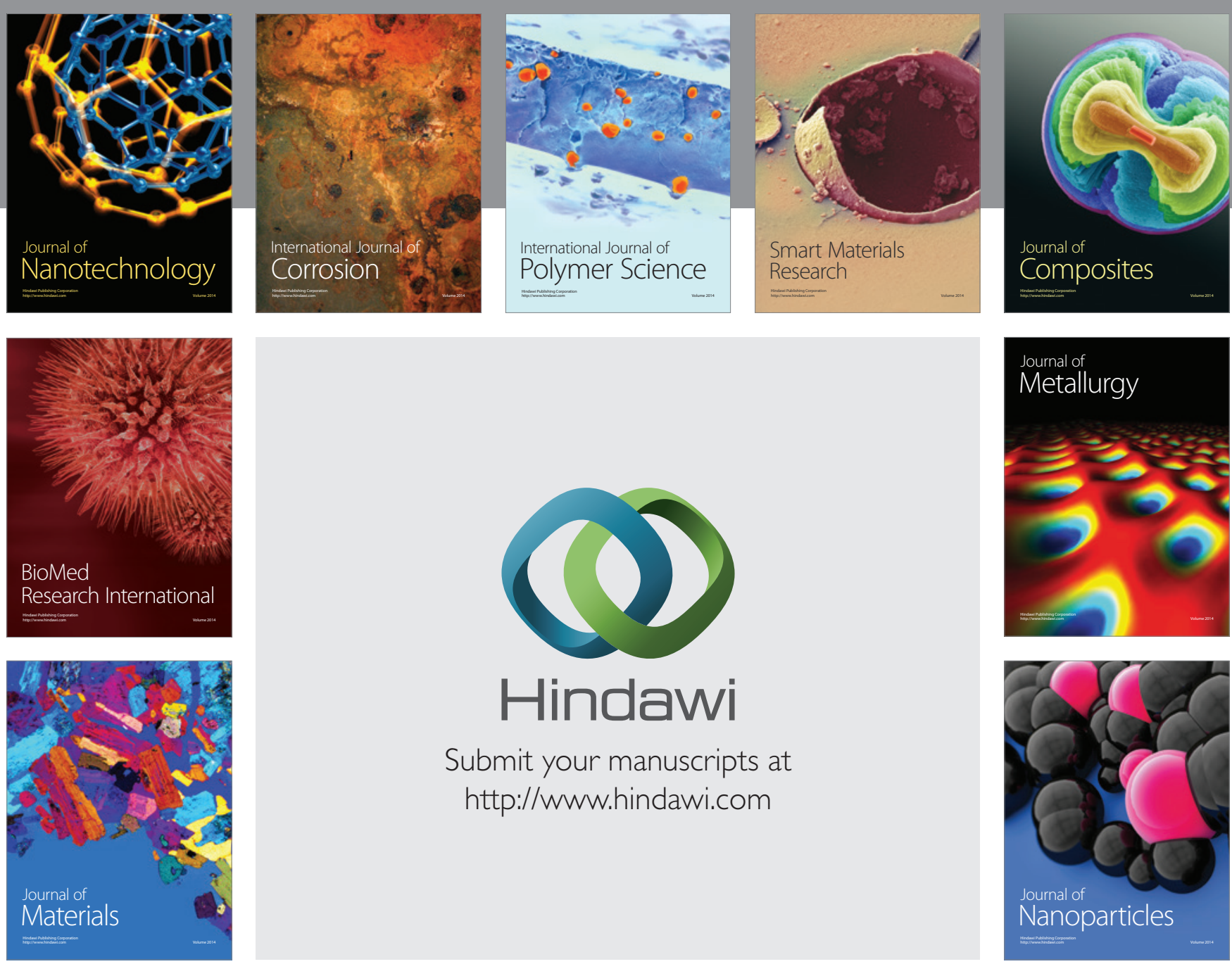

Submit your manuscripts at http://www.hindawi.com
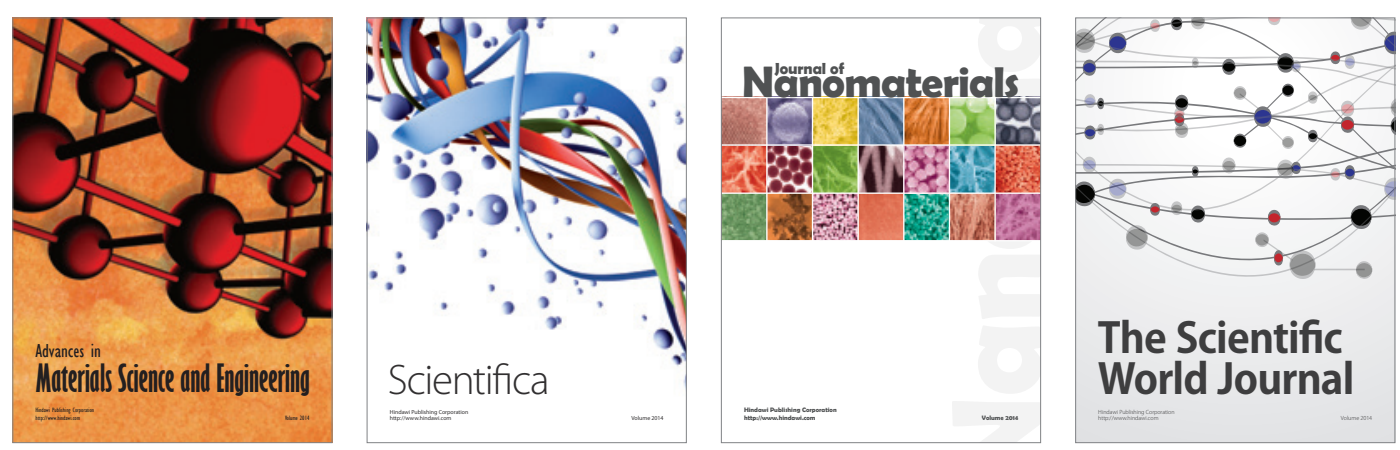

\section{The Scientific World Journal}
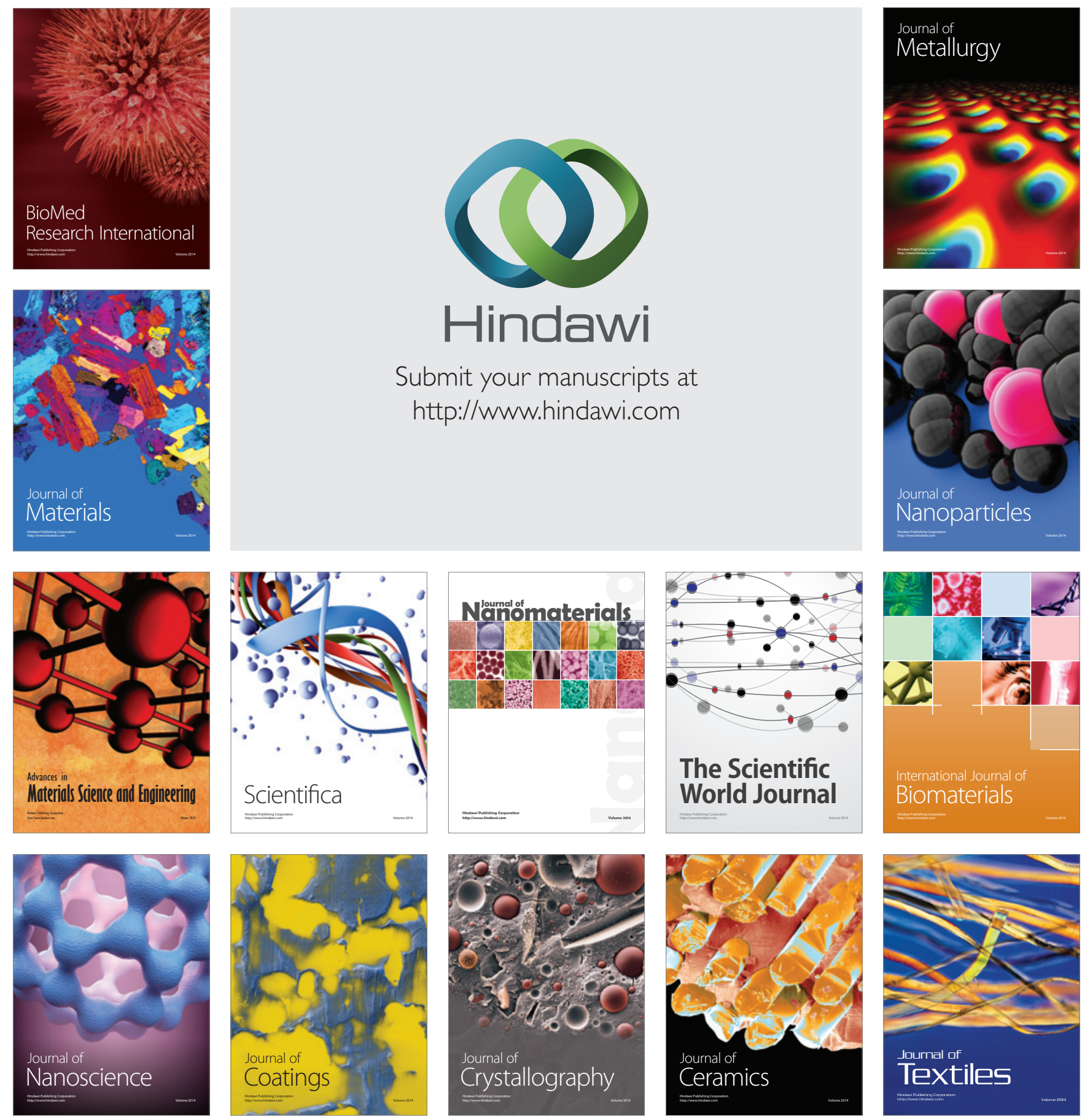